\title{
Midwest Reaches for the Stars
}

Dr. Ellsworth is director, and Mr. Kilpatrick, associate director in charge of technical processes, State University of Iowa Libraries.

TN 1940 the presidents of 13 Midwest uni1 versities expressed their interest in a cooperative storage library for the Midwest. A survey, financed by the Carnegie Corporation, was made and published. Aspects covered were problems concerned with the transfer of books, cost figures, plans of incorporation, and objectives.

This plan came to naught for reasons unknown to us. The war, the constitutional inability of librarians to agree on anything, the inherent weakness of the storage library idea by itself, plus the basic philosophies of the librarians concerned were probably the relevant factors.

Once more in 1947 the presidents of the Midwestern universities have suggested that we librarians open the question. There is no war, there is more knowledge about the storage idea, librarians agreed on one point and found that it didn't kill them, and there is a new generation of librarians in 13 of the Midwestern universities-some of us imbued with the graduate library school experimentation, the rest, wise, fearless, and scholarly. In fact, with men like Doane, Miller, Warner Rice, Pargellis, Parker, Henkle, McDiarmid, Hazen, Moriarity, Nyholm, Orr, Manchester, Towne, and Downs, it is inevitable that the dragons will be slain. We have our St. Georges, our doubting Thomases, our Don Quixotes, but

1 Paper presented by Dr. Ellsworth at the Conference of Eastern College Librarians, Columbia University, Nov. 29, 1947. also; as a group, we have a fairly honest common understanding of scholarship and its bibliographic implications.

So now, under the chairmanship of President Colwell, a new committee consisting of Presidents Colwell, Fred, and Wells, and librarians McDiarmid, Doane, and Ellsworth, is at work with two subcommittees appointed. One is making a fresh survey, and one is studying centralized cataloging and acquisition.

The contents of this paper represent only the personal opinions of the authors. We are the subcommittee on cataloging and acquisition. The concepts we state have not been submitted to or approved by our committee.

\section{The Regional Idea}

Now, a few preliminary statements about the regional idea are in order. We are well aware that there is a kind of psychological disorder which causes a man who cannot solve his personal problems to turn to grandiose schemes which are often nearly perfect in themselves, but which lack a few connecting links with reality, and the lack destroys the validity. It is often difficult to distinguish, at any given time, between the efforts of a man who has a toe hold on a truly great idea to a man whose toes, all ten of them, are up in the clouds.

We librarians have a bit of this disorder in our blood. We turn to the "larger unit of service" idea, in part, because of its sweet reasonableness, but also because we cannot or will not meet our own problems on their home grounds. 
Example 1. We cannot or will not agree among ourselves in the large libraries on a division of collecting policies, because at heart we are all bibliographic empire builders. Therefore, we turn to Farmington, because we sincerely hope it will permit us to eat our cake and have it, too.

Example 2. The small public library turns to the county or regional idea, because the town cannot afford a librarian. But it can afford teachers, preachers, lawyers, doctors, and dentists. What we mean is that we can't convince the citizens that they want to pay for a librarian. But when we get a county or regional librarian, have we really convinced the citizens that they want her, or have we merely spread the cost so that the citizens are not conscious of it, or the librarian?

Example 3. In a given metropolitan area, we have two medium-sized universities and a few small colleges. Just what do we add to the intellectual resources of the group when we make a regional library center out of them, unless in so doing we succeed in causing them to eliminate unnecessary duplication and thereby purchase additional teachers and books they would otherwise not have?

Example 4. We speak glibly about eliminating duplication in collecting fields. We are keen on the idea, but we think in an academic vacuum. We seem unaware that our plans might have curricular implications, the results of which we would be unable to face. Let us take a state university and a nearby state college of agriculture. The professor of poultry diseases at the state college publishes his research in the highly specialized poultry journals which the university does not have or need. But his research is based on data which he can get only from the basic science and medical journals, which we librarians would like to think the university and not the state college should own. This cannot be. Both institutions must own them. The poultry journals are cheap, but the others are not. Supposing the university creates an institute of atomic research and the other an institute of nuclear physics. Will they not require the same literature? Could either exist without the literature?

Our basic objective is to see what can be done regionally either to make our money go further, or to increase the quantity and quality of printed research and instructional facilities in the Midwest within a ten-year period-because after that we'll probably be defending the status quo.

At the very beginning we must have the librarians' and their institutions' stand on one basic issue, "Are we prepared to discard our inherited philosophy of trying to make each of our libraries as large and inclusive as possible in favor of a philosophy of building the contents of each of our libraries in relation to the inclusive contents of a group of homogeneous libraries?" If the answer is yes, we can proceed to an examination of the pig in the poke, but if it is no, then there is no use starting. The reason we shall insist on this declaration of intention is that practical experience has shown that a group can never reform itself, unless its members wish to do so.

This question sounds simple. It is not, as you can see from the following examination of its ramifications.

\section{Implications}

First, the legal aspect. Regional cooperation is going to mean that local funds will be sent outside of the state to pay for books that are going to be located outside of the state. This issue can be dodged at first by calling it payment for bibliographic service, but sooner or later it must be faced directly, even if new state legislation is necessary. We are leaving this up to our 
presidents, because they got us into this, and they can get us out.

Previous commitments made in terms of special collections will limit our freedom to act, but will not stymie us seriously.

Second, the curricular implications. The direction we take will determine the nature of the problem. If we go in the direction of assigning special collecting fields to each of us, then in time these collections will become so strong as to fix the research focal points of our universities. Or else, they will be white elephants to us.

If Iowa, for example, is to have the one complete collection in psychology, one of its strongest departments today, then the university should make this the strongest psychology department in the Midwest, and everyone concerned should accept this as a responsibility to be met no matter what the effect is upon the research welfare of Iowa's other departments in war or peace, in prosperity or depression.

This has two implications, one internal and one external.

- First, it implies that the other departments in our university will operate at a somewhat narrower scope-all at the Ph.D. level to be sure, but with beer instead of champagne.

Second, it implies that the other universities will keep their psychology departments limited in favor of the subjects they are to operate on an unlimited basis.

Would we accept this idea? And do our presidents, deans, and faculties understand it?

\section{A Midwest Library Center}

This is only one possible direction. The other would be for us not to build exhaustive collections in any field on any of our campuses, except in special libraries or in special cases, but rather to make our campus collections working libraries for teaching and research, and to build the exhaus- tive collections in the Midwest library center. If this were done, we could cull out little used materials, dead or alive. We could begin positive acquisition by placing all our foreign importations that come from the Farmington Plan, and buy for campus use only the foreign titles our faculty request.

Such a plan would not force our research curricula in any direction. We would be free to build working research collections in any or all fields, but we would be freed of the necessity of acquiring and maintaining the little used, elusive, minor publications for any or all of our fields. These would be in the center, paid for cooperatively by all of us.

In periods of severe depression, we would not have to starve most of our departments in order to meet commitments for a few departments. We would merely ask all to go on a moderate diet.

In normal times we would not be in the position of controlling the introduction or shift in emphasis of research programs. Nor would we be required to support an exhaustive research collection that had grown apart from faculty development.

Neither would we be denying researchers access to an exhaustive collection in their field. This would be available to them in Chicago; not on our campus.

If we do this, and we hope we shall, then let us be frank in admitting that some day in Chicago we shall have a great research library that will dwarf all our campus libraries in importance.

\section{Effect on Chicago University}

Let us admit also that if this center is located on the campus of the University of Chicago, as I hope it will be, that its presence will increase the prestige and resources of the University of Chicago, and will give it an advantage over the rest of us. Its presence also gives the University of Chi- 
cago a chance to become a great intellectual host to scholars in the region.

Is this a good or bad thing for Iowa or Northwestern or Illinois? That will depend on one's point of view.

The university could extend some very real and useful courtesies to scholars who come to use the center. It could allow them access to the faculty club. It could encourage them to feel at home among the resident faculty in their subject field. By cultivating this kind of faculty relationship, we believe the entire region would profit.

\section{Nature of the Center}

The nature of the library center will be determined by the collecting policies we adopt. Its services should include lending and copying of all types. It should be connected to each of us by either teletype, leased telephone wire, facsimile reproduction, radio, or television. Deliveries by air mail should be common. It might well have a translation service.

It should obviously contain special study facilities for visiting scholars and should have a complete set of bibliographic tools and a staff of expert bibliographers.

The concept of ownership between it and us should be so fluid that any local condition can be met.

Travel expenses for scholars from each library should be anticipated and handled locally so that red tape is avoided and so that the scholar does not need to beg.

In addition, the center should be tied into the needs of the smaller colleges of the region at a level consistent with their needs. The financial relationships should be so flexible and simple as to encourage use.

Third, the technical processes aspect, and now we come to the pièce de résistance. We should be smart enough to centralize a large share of the purchasing and cataloging of the participating libraries at the center.

\section{Centralized Acquisition and Cataloging}

For some time now, along with most other sensible librarians, we have been convinced that we needed a basically new approach to the cataloging problem. It has seemed reasonable that we should centralize cataloging nationally. We are now convinced that this won't be done, because there is too much inertia to overcome, that no agency that must catalog for all types of libraries can do the job (we refer to the Library of Congress), and that it cannot be done unless the centralizing agency can at the same time include acquisitions. The latter is obviously impossible on a national basis.

But the regional approach for a group of homogeneous libraries looks promising. We are trying to sketch out methods of centralizing cataloging and acquisitioning. Our report will be made to the Midwest committee during the winter.

We wish to describe our proposal in enough detail to show you what we are up to, without pretending that we know how to solve all the difficulties that have to be overcome, or that our committee will find the proposals acceptable. We must necessarily wave a magic wand here and there to cause a few embarrassing rabbits to appear and disappear at our convenience. That is legitimate at this stage of development, though it would be intolerable later.

First, we offer a few general observations and assumptions.

One, it seems absurd for each of the Midwest libraries to catalog and classify collections of which approximately 60 per cent are common to all.

Two, cooperative cataloging is no answer, because most librarians think it represents an added cost.

Three, there are four reasons why present day use of printed L.C. cards does not permit us to lower our costs significantly, 
(a) cards are available for only approximately 65 per cent of the materials we acquire; (b) we consider it necessary to make changes on many of these cards; (c) we consider it necessary to adapt the recommended classification numbers on the card; and (d) those who furnish cooperative cataloging copy must initiate an expensive process.

Four, if we are to receive the maximum benefit from centralized acquisition and cataloging, we shall have to be willing to accept a uniform assignment of classification numbers and entry form. Likewise, a uniform assignment of subject headingsif we continue our present system of subject cataloging, which I assume reluctantly.

Five, our basic objective is twofold: one, to provide each of us with a union list of our joint holdings, and two, to free each of us of a large share of our present cataloging costs and to a lesser extent of our acquisition costs.

Six, we propose to centralize acquisition not because we expect sizable savings, but because it is a necessary element in centralized cataloging. And now to the proposals :

Plan I. The center would purchase, process, catalog, and mark each publication acquired by the participating libraries and send it along ready for the shelf.

Since it is probably true that the largest share of acquisition cost comes from the selecting function, the center will try to reduce this as much as possible by making advance arrangements with publishers for automatic supplying of new publications according to the nature of the publication and the wishes of each university. Each library will retain the right to acquire and ignore what it wishes, but the center will have enough high quality personnel to enable it to engage in selecting for each library in areas where this is possible.
Sovereignty, nevertheless, stays in each library.

A direct means of conversation communication between each library and the center will be established, so that confused order requests can be handled directly with no wasting of time through letter correspondence.

The center will develop a union list of the holdings of its participating libraries, using a system of Kardex Visible Index on panels which can be kept either on circular posts, in tubs, or in letter file cabinets. The basic size of the entry slip on the visible index panels might be $I^{\prime \prime} \times 8^{\prime \prime}$, though the height of the slip can vary from $\frac{i}{4}:$ to the height of the panel. Each entry will include the classification number, and the bibliographic data for each item. The bottom line of each slip will contain a row of numbers from I to 40 , each being the symbol for one of the participating libraries. Ownership for each title will be indicated by checking the library's number on each slip.

\section{Basic Catalog}

When the holdings of the libraries have been recorded (and here we wave our wand) each panel will be photographed and reproduced by the most appropriate method -photo-offset, enlarged microprints, or Ozalid prints, and the resulting sheets gathered together in volumes and sold to the libraries. We might call this our basic catalog.

This will be each library's identification catalog of its own holdings, as well as for the holdings of the other libraries in the region. Each library will no longer use its own card catalog for this purpose and will discard its identification cards.

\section{Additions}

Additions of new titles by the libraries 
will be recorded in the visible index master file, either by adding a new entry, or checking ownership as the case may be. There are several ways in which this information can be put into our campus copies of the printed basic catalog. One, each panel could be reproduced as it is changed and new prints sent out to the libraries. Two, a system of cumulative supplements could be used with a new edition of the basic cata$\log$ every ten or twenty years.

\section{Individual Library Records}

Each library will need to keep a record of its new additions until such time as the record is incorporated into the printed catalog. This could be done in one of several ways. If the title is already listed in the basic catalog, the library would need only to check its number on the relevant card. If the title is not in the catalog, a small card file would be kept until such time as each entry is incorporated in the basic catalog. It will already have such a card from the order process.

Ordering would be done by a typical multiple card order system-copies of which would go to the center and additional copies would remain in each library for whatever use it cared to make of them. Accounting for each library would be done at the center.

Since the Kardex Visible Index panel is flexible in terms of the size of card it will accommodate, it would be feasible to include the necessary cross references for identification, and, of course, we could include title entries if we wished.

\section{Subject Cataloging}

For the time being the following method of handling subject cataloging would be used. The center would compile sets of guide cards with L.C. subject headings (plus improvements) printed on the tabs.
Each library would buy a set and use this for forming a new subject catalog. Behind each guide card it would file the relevant subject cards it now owns. Its own set of cross references would be discarded.

In the future when new processed books come from the center, they will contain the right number of printed cards to be filed in the subject catalog, but no headings are to be typed on these cards. Each will be filed behind its appropriate subject guide tab.

This method of handling subject headings (as well as "See" and "See also" references) will simplify the business of keeping them up to date. When a change is in order, the center will merely print new guide cards, and send us copies. We will pull the old guide and its accompanying cards. We discard the guide, and file the new guide, and the accompanying cards in their correct alphabetical place. Current changes in subject cross reference will come from the center.

Each library can do as it pleases with special card indexes of purely local matters. If it wishes to have these, it may do so at its own expense.

Each library could do as it pleased with the subject guide cards that are not represented by books in its library. We would leave them there for book selection purposes, if for no better reason.

\section{Standardized Classification}

Now on the basis of this bird's-eye view of a new proposal, we are ready to claim that we could live with standardized classification. Many of the local adaptations that are necessary are shelving problems anyway, not classification problems. Other local adaptations are indulgences just to please someone. We are ready to say that we cannot afford these, because the values 
we get out of them are not very high. This problem should be looked up by someone not hindered by library bias.

Campus location symbols could be added to the identification catalog, and the number of copies owned could be recorded there or in the shelflist, which could be just an extra card furnished by the center. By the way, the center would get these cards from L.C. if available, or it could make its own, or even make its own instead of buying from L.C.

\section{Standardized Subject Headings}

Difference of opinion will exist on the centralized classification question, and we will have to count noses sooner or later, but on the question of centralized subject headings as suggested, we fail to see how much of an argument can be developed. Perhaps we are wrong.

\section{Effect of Project on Staffs}

What effect would all of this have on our staffs? We would each need a high class bibliographic expert to coordinate the remaining parts of acquisition, cataloging, and bibliographic service. We would need a small staff of filers. The professional members of our order and catalog staffs would be absorbed, in part, by the center, and in part by finding positions in other libraries in other parts of the country, not so fortunate as to be located in the Midwest.

\section{Effect on Library Profession}

What effect on the library profession? Well, we all admit now that the primary source of our procurement difficulties lies in our inability to keep high-powered librarians interested, because we can't separate professional work from clerical duties. This project would make a dent on that problem.
Plan I, as you might guess from reading between the lines of my statement, calls for a complete recasting of the entire purchasing and cataloging system now being used. This is bitter medicine, and is going to be considered radical, Utopian, unrealistic, etc. We are so convinced that drastic measures are called for that the idea no longer frightens us. But others in our midst will react differently.

\section{Second Proposal}

Therefore, we propose a second plan for centralization that accepts the present card system, that can be expanded in scope as our group is ready to expand, and that avoids the use of standardized classification and subject headings. Plan II relies upon the printed card system as now used.

The center would develop a union card catalog of our respective holdings, but this would not be reproduced. It would be used mostly for ordering purposes and for the answering of inquiries for interlibrary loan purposes.

Purchasing, processing, and cataloging, but not classification would be done in the center, and books that come to us from the center would have the catalog cards in them. The center would secure L.C. cards if they are available, or it could compose its own. Each library, if it insists, could apply its own classification and subject headings.

It should be obvious that the only economy in this plan, in terms of cataloging costs, comes from central cataloging of the books for which libraries are unable now to secure printed cards from the Library of Congress-approximately 40 per cent, we are told. There might be other economies resulting from central purchasing, but these would never be large and might not exist at all.

Now if we would accept centralized clas- 
sification and subject heading assignments from the center, in other words if we would get our cards all ready for the catalog, the economies would be greater, but the task of reconciling present and past records in card form would be complex and perhaps impossible.

Thus, although we are going to develop such a plan, we are probably going to say that our group should either go all the way, or do nothing at all. We are pretty well convinced that in this situation half way measures will probably serve only to add further confusion to an already chaotic condition.

If the Midwest committee is willing to consider the idea of a basically new plan, we shall find ways of studying and solving the problems that must be faced before any new plan could be approved. The problem is not so much one of stubborn details as it is one of agreeing upon fundamental values, and being willing to give up small advantages for the sake of securing large values.

\section{Coordinating Subject Cataloging and Bibliography}

Later on we should hope that we would address ourselves to the problem of subjecting the relationship between subject catalogs, printed bibliographies, and abstracting services to fresh, unbiased, scholarly scrutiny. But for the time being, we consider it wise to concentrate our attention on straightening out a program of identification cataloging, and ordering. The two problems are quite different in nature, and probably will require different organization and publication media.

\section{Midwest Library Center and the Farming- ton Plan}

We wish to close this paper by going back to the regional concept in relation to the Farmington Plan. For some time now in the Association of Research Libraries, we have debated the merits of the Farmington Plan, and we have had difficulties because the plan forces us to face up to issues which we do not wish to face or know how.

Our original plan was to assign subject priorities to each library and to make each library accept responsibility for building exhaustive research collections in its priority subjects. We had two objectives: first, to get one copy of everything into the country, and second, to encourage libraries to specialize and to avoid the alleged evils of the present situation which are that we all more or less specialize in the same fields and all ignore the same fields.

We assumed that each university would continue to build large collections for research, but that each would build exhaustive collections in only a few fields, and that these would be divided among the libraries.

If the priorities were to be assigned in broad areas, such as chemistry, modern Russian history, or physics, only the largest libraries could afford to accept such broad responsibility. If the broad fields were to be divided into narrow units, there would be practical difficulties from the point of view of the dealers in getting the books where they belonged, and from the point of view of the librarians, in building expensive subject catalogs to tell scholars where the books are.

Those libraries that were assigned priorities that coincide with major research programs in their universities could justify more or less perpetual commitments in favor of these subjects, because they could assume that their institution would be willing to remain strong in those fields-even at the expense of other departments. But the libraries that could not afford broad and expensive priorities would inevitably have to take subjects that would not be matched 
by active research work in their universities. Their librarians hesitated because it seemed illogical, even for the good of the cause, to put money where it would not produce local results.

The miserable part of all this is that we do not really wish to build diversified specialized libraries (beyond certain obvious exceptions) because we know perfectly well that all our universities are going to follow pretty much the same curricular patterns in research (with specific exceptions) and in about the same relative proportions. They will differ more in level of attainment than they will in diversity of effort. These things are determined by factors which are not necessarily subject to the control of the university administrations. This explains why much of our talk in the A.R.L. is so hollow. We really care very little about these minor publications if their acquisition costs us very much.

The second variation in the Farmington Plan was based on a frank realization of these facts. This was the regional idea. 'This said, let us do what we believe in doing; namely, buy selectively what we think we need in our libraries to support the research activities that are thriving now without regard to what the other universities do. Let us next admit the validity of importing one copy of foreign books, but let us do so in the least expensive and most convenient manner, which would be to put them all in one place so we would know where they were, and would, therefore, not need to build an expensive catalog to locate them. That would logically be at the Library of Congress. But this is a big country and Washington, D.C. is number one target for an atomic bomb, so we said, let us import as many as three copies and spot them regionally, and pay for each of the three collections cooperatively on a regional basis. But there are no regional libraries at the present time, so for the first year we would import only one copy and put it in the Library of Congress, and let the future take care of itself. That is where we are today.

\section{Summary}

If in Chicago we can have a Midwestern library center that will do the following things :

I. Become a reservoir collection of Farmington importations plus all of the little used materials we wish to get out of our respective collections.

2. Supply us with a union catalog of its and our holdings.

3. Enable us to get rid of a significant per cent of our technical processes costs by doing centralized purchasing and cataloging for us.

4. Supply us with the kind of bibliographic service mentioned earlier in this paper.

Then the Midwest will gain because it will have more books than it now has and better bibliographic service than it now has.

The Universities of Iowa, Illinois, Minnesota, and others will gain because we will have to buy less marginal material, we will get rid of a large share of our technical processes costs, we can buy more of the books needed for present day teaching and research, and we can keep the size of our libraries down to where we want them. We will be meeting the problem of library specialization in the only way it can be met honestly and permanently.

Thus, it comes out that our collecting problems are tied up with our cataloging problems. Our cataloging problems can be solved only through centralization. Centralization of cataloging can be done advantageously only when accompanied by central purchasing. Central purchasing can be done advantageously on a unit no larger than the region. So the region is the place to start, and the Midwest is the region in which to start. 